\title{
Onychomykose
}

\section{Wenn der Nagel der Lackierte ist}

\author{
Infektionen mit Nagelpilzen sind ein \\ Volksleiden: In manchen Studien sind \\ Prävalenzraten von bis zu $26 \%$ er- \\ rechnet worden. Um eine Bagateller- \\ krankung handelt es sich nicht. Das \\ Selbstwertgefühl der Betroffenen \\ wird schwer in Mitleidenschaft gezo- \\ gen - bis hin zu Depressionen. Dabei \\ existiert eine ganze Palette an Thera- \\ pieoptionen, darunter Antimykotika \\ in Lackform.
}

— Häufigste Erreger von Onychomykosen sind Dermatophyten wie Trichophyton rubrum und Trichophyton mentagrophytes. Auf ihr Konto gehen bis zu $90 \%$ aller Fälle. Der Pilzbefall von Nägeln ist für die Patienten weit mehr als nur ein kosmetisches Problem, wie Chander Grover und Ananta Khurana (Universitätsklinik Delhi, Indien) in ihrem aktuellen Reviewartikel in der Fachzeitschrift „Mycoses“ betonen. Die sozialen und emotionalen Probleme können enorme Ausmaße erreichen, besonders wenn die Fingernägel betroffen sind. Am meisten leiden Frauen, junge und gebildete Menschen sowie Stadtbewohner.

\section{Unbedingt behandeln}

Doch es drohen auch körperliche Folgen. Die Pilze können sich auf weitere Nägel ausbreiten oder Schmerzen verursachen - etwa beim Gehen. Chronische Mykosen im Fußbereich gelten als Risikofaktor dafür, akute bakterielle Phlegmonen an den Beinen zu entwickeln.

Die Frage, ob Onychomykosen zu behandeln sind, lässt daher nur eine Antwort zu: unbedingt! Grover und Khurana nennen fünf Optionen, die der Behandlung offenstehen:

- topische Therapie

- systemische Therapie

- chirurgisches oder chemisches Débridement

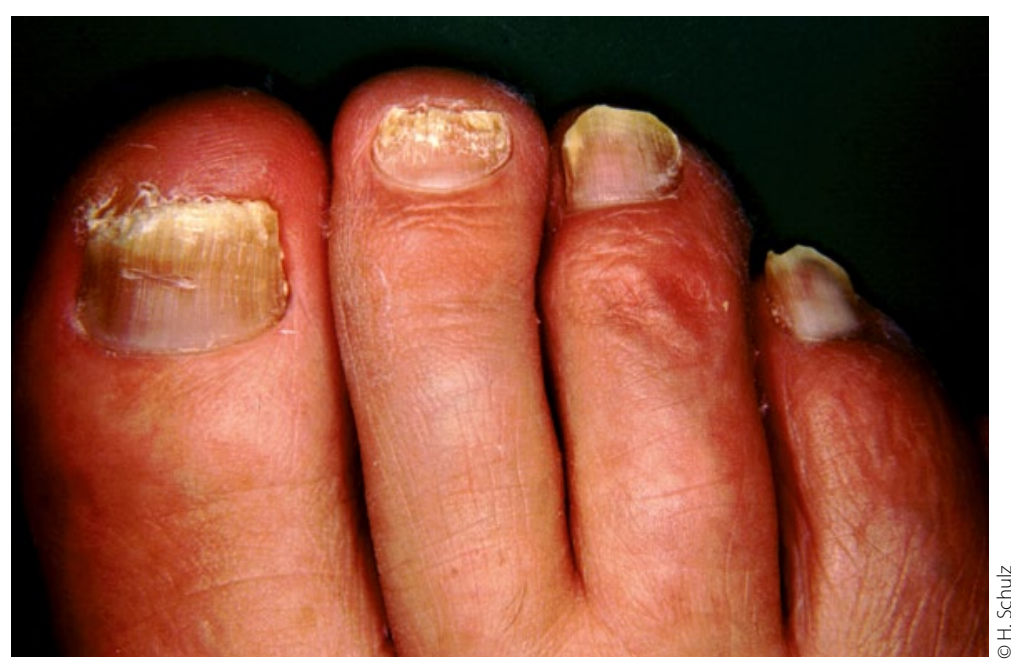

Distale subunguale Onychomykose bei einem 59-jährigen Mann.

- gerätegestützte Methoden wie Laser, Lichttherapie oder Penetrationsverstärker (Iontophorese, Ultraschall, Microporation)

- Kombinationstherapien.

\section{Topische Therapie}

Für die topische Therapie stehen beispielsweise ciclopirox- oder amorolfinhaltige Präparate in Lackform zur Verfügung. Dadurch ist für längeren Kontakt der Wirksubstanz mit dem Nagel gesorgt. Zudem erhöht das Verdampfen des Lösungsmittels die Wirkstoffkonzentration. Die Indikation zur topischen Therapie besteht laut Grover und Khurana, wenn

- eine distale subunguale Onychomykose besteht, die weniger als $50 \%$ des $\mathrm{Na}$ gels umfasst und nicht die Nagelmatrix befallen hat, ohne gelbe Streifen am lateralen Rand und ohne Dermatophytome; - es sich um eine klassische weiße superfizielle Onychomykose handelt;

- Schimmelpilze die Verursacher sind, ausgenommen saprophytäre Aspergillen;

- die Patienten eine orale Therapie nicht tolerieren;
- nach einer oralen Behandlung der Bedarf für eine Erhaltungstherapie besteht.

\section{Prognosefaktoren}

Die Behandlung der Onychomykose ist langwierig und erfordert eine zuverlässige Mitarbeit des Patienten. Dennoch sind die Ergebnisse nicht immer voll befriedigend. Totale Nageldystrophie, Beteiligung der lateralen Nagelkante, dicke Nagelplatte ( $>2 \mathrm{~mm}$ ) und Dermatophytome sind Faktoren, die mit einer reduzierten Prognose einhergehen. Ältere und immunsupprimierte Patienten oder solche mit verminderter peripherer Zirkulation haben ebenfalls eine schlechtere Prognose. Gleiches gilt, wenn zusätzliche Dermatosen, beispielsweise eine Nagelpsoriasis, bestehen.

Die generellen Ansprechraten der systemischen Therapie liegen bei $80 \%$. Um die Situation zu verbessern, wird vermehrt auf Kombinationstherapien, z. B. mit systemischen plus topischen Substanzen, zurückgegriffen.

$\mathrm{RB}$ -

- Grover C, Khurana A. An update on treatment of onychomycosis. Mycoses 2012; DOI: 10.1111/j.1439-0507.2012.02199.x 